\title{
Pencegahan Terjadinya Delayed Cerebral Ischemia (DCI) pada Pasien Aneurysmal Subarachnoid Hemorrhage (aSAH) di Intensive Care Unit
}

\section{The Prevention of Delayed Cerebral Ischemia (DCI) in Aneurysmal Subarachnoid Hemorrhage (aSAH) patient in the Intensive Care Unit}

\author{
Daryanto Tri Winarko ${ }^{\bowtie}$, Prananda Surya Airlangga, Eddy Rahardjo \\ Departemen Anestesiologi dan Reanimasi, Fakultas Kedokteran, Universitas Airlangga/RSUD \\ Dr. Soetomo, Surabaya, Indonesia
}

${ }^{\square}$ Korespondensi: daryantotriwinarko@yahoo.com

\begin{abstract}
Background: The most cause of non traumatic subarachnoid hemorrhage (SAH) is ruptured aneurysm (75\% - 85\%). This condition is life-threatened and needed a neurocritical care, while the delayed cerebral ischemia (DCI) is serious complications of SAH and relate to the adverse neurological outcomes. Cerebral Vasospasm is the main cause of DCI, it most occur in the 7th-8th days after hemorrhage. The patients with high blood pressure, active smokers, alcoholics, women and 40-60 years aged are risk to suffere the aneurysmal subarachnoid hemorrhage (aSAH).

Case: There were 3 cases of aSAH reported. The first and the third cases were not lossing the conciousness which based on the fisher modification scale were risking of vasospasm scale 2 or medium risk, and the mortality rate (based on Hunt and Hess) of both cases were $40 \%$. The second case was lossing the conciousness which had the risk to suffere from vasospasm scale 2 or medium risk, but the mortality rate was $50 \%$. After the SAH diagnose enforced, all the three cases were immediately get the nimodipin therapy to prevented the vasospasm besides the fluid status had to be euvolemic and sistolic blood preassure was 120-140 $\mathrm{mmHg}$.

Discussion: aSAH had a high mortality rate and permanent disability rate. Cerebral aneurism could be detected when it was ruptured or when the CT scan test and accidental magnetic reconance imaging (MRI). The mortality usually caused by neurological injuries of early hemorrhage, rebleeding and DCI. The aim of managing the aSAH rupture was to prevent the rebleeding and DCI with nimodipin therapy, maintaned the normal blood volume (euvolume) and to maintained the sistolic blood pressure around 120-140 $\mathrm{mmHg}$.

Conclusion:To prevent the occurance of aSAH, the screening of aneurism will be better and cost saving. The nimodipin therapy aims to prevent the DCI in aSAH, to mantain the normal blood pressure and slight of hypertension blood pressure (120-140 $\mathrm{mmHg}$ ).
\end{abstract}


Keywords: aneurysmal subarachnoid hemorrhage (aSAH); delayed cerebral ischemia (DCI); intensive care unit; prevention; vasospasme

\begin{abstract}
ABSTRAK
Latar Belakang: Penyebab subarachnoid hemorrhage (SAH) non trauma terbanyak adalah pecahnya aneurisma (75\%-85\%). Hal ini merupakan kondisi yang mengancam jiwa dan memerlukan perawatan neurokritikal, sedangkan delayed cerebral ischemia (DCI) merupakan komplikasi serius dari SAH dan berhubungan dengan hasil neurologis yang merugikan. Vasospasme serebral adalah penyebab utama terjadinya DCI, paling sering terjadi pada hari ke 7-8 setelah perdarahan. Penderita tekanan darah tinggi, perokok, peminum, wanita dan usia 40-60 tahun berisiko menderita aneurysmal subarachnoid hemorrhage (aSAH).

Kasus: Terdapat 3 kasus aSAH yang dilaporkan. Kasus pertama dan ketiga tidak mengalami penurunan kesadaran yang menurut skala modifikasi fisher berisiko terjadi vasospasme berskala 2 atau berisiko sedang dan angka mortalitas (menurut Hunt dan Hess) keduanya sebesar $40 \%$. Sedangkan kasus ke 2 terjadi penurunan kesadaran yang mempunyai risiko terjadi vasospasme berskala 2 yakni berisiko sedang, namun angka mortalitasnya 50\%. Ketiga kasus setelah diagnose SAH ditegakkan segera mendapatkan terapi nimodipin untuk pencegahan terjadinya vasospasme disamping status cairan harus euvolemi dan tekanan darah sistole 120-140 mmHg.

Pembahasan: aSAH mempunyai angka kematian dan tingkat kecacatan permanen yang tinggi. Aneurisma serebri dapat terdeteksi ketika pecah atau saat pemeriksaan CT scan dan magnetic reconance imaging (MRI) yang tidak disengaja. Kematian biasanya disebabkan oleh cedera neurologis akibat perdarahan awal, perdarahan ulang (rebleeding) dan DCI. Tujuan pengelolaan pecahnya aSAH adalah untuk mencegah terjadinya perdarahan ulang dan DCI dengan menggunakan terapi nimodipin, mempertahankan volume darah normal (euvolume) dan mempertahankan tensi sistolik sekitar 120-140 $\mathrm{mmHg}$.
\end{abstract}

Kesimpulan: Untuk pencegahan aSAH tindakan skrining aneurisma akan lebih baik dan dapat menghemat biaya. Sedangkan pencegahan terjadinya DCI pada aSAH dilakukan dengan pemberian obat nimodipin, mempertahankan sirkulasi darah normal dan tekanan darah sligh hipertensi (120-140 $\mathrm{mmHg})$.

Kata Kunci: aneurysmal subarachnoid hemorrhage (aSAH); delayed cerebral ischemia (DCI); intensive care unit; pencegahan; vasospasme

\section{PENDAHULUAN}

Insiden subarachnoid hemorrhage (SAH) diseluruh dunia diperkirakan 9/100.000 orang pertahun dengan variasi lokal. ${ }^{1,15}$ Pada tinjauan sistematis ditemukan insiden tinggi di Finlandia $(19,7 / 100.000$ orang/tahun) dan Jepang $(22,7 / 100.000$ orang/tahun) sedangkan insiden rendah dilaporkan di Cina
(2/100.000 orang/tahun). ${ }^{1,4,14}$ Kejadian SAH hanya 5\% dari semua stroke tetapi mempunyai angka kematian dan tingkat kecacatan permanen yang tinggi. $1,3,6$

Insiden kasus baru SAH di Amerika Serikat terdapat sekitar 30.000 pertahun atau 10/100.000 orang/tahun. Penyebab $\mathrm{SAH}$ non trauma terbanyak adalah 
pecahnya aneurisma (75\%-85\%), merupakan kondisi yang mengancam jiwa dan memerlukan perawatan neurokritikal, sedangkan delayed cerebral ischemia (DCI) merupakan komplikasi serius dari SAH dan berhubungan dengan hasil neurologis yang merugikan. Vasospasme serebral adalah penyebab utama terjadinya $\mathrm{DCI}^{7,10}$, paling sering terjadi pada hari ke 7-8 setelah perdarahan. ${ }^{8}$ Risiko terjadinya aneurysmal subarachnoid hemorrhage (aSAH) terutama pada penderita tekanan darah tinggi, perokok, peminum dan wanita serta usia $40-60$ tahun. ${ }^{15}$

Insiden aSAH berdasarkan ras dan etnis terdapat perbedaan, orang kulit hitam dan hispanik memiliki insiden lebih tinggi daripada orang kulit putih amerika. ${ }^{4}$ Kasus aSAH di RS Mitra Keluarga Surabaya terdapat 15 kasus (2016) dan 10 kasus (2017). Pada aSAH, terjadinya risiko vasospasme dapat dinilai dengan menggunakan skala fisher (Tabel 1). Sedangkan untuk mortalitas menggunakan sistem penilaian "Hunt and Hess Scale" (Tabel 2).

Tabel 1. Skala modifikasi fisher dan tingkat risiko vasospasm ${ }^{6,7}$

\begin{tabular}{cl}
\hline Scale & \\
\hline 0 & No SAH or IVH: very low risk \\
1 & Focal or diffuse thin layer of SAH,no IVH: low risk \\
2 & Focal or diffuse thin layer of SAH,IVH present:moderate risk \\
3 & Focal or diffuse thick layer of SAH, no IVH:high risk \\
4 & Focal or diffuse thick layer,IVH present:very high risk \\
\hline
\end{tabular}

Tabel 2. Skala Hunt dan Hess

\begin{tabular}{|c|c|}
\hline Grade & Description \\
\hline 1 & Asymptomatic or minimal headache and slight nuchal rigidity \\
\hline 2 & $\begin{array}{l}\text { Moderate to severe headache, nuchal rigidity, no neurological deficit other than } \\
\text { cranial nerve palsy }\end{array}$ \\
\hline 3 & Drowsiness,confusion,or mild focal deficit \\
\hline 4 & $\begin{array}{l}\text { Stupor,moderate to severe hemiparesis,possible early decerebrate rigidity and } \\
\text { vegetative disturbances }\end{array}$ \\
\hline 5 & Deep coma,decerebrate rigidity, moribund appearance \\
\hline
\end{tabular}

Tabel 3. Tingkat mortalitas berdasarkan skala Hunt dan Hess

\begin{tabular}{ll}
\hline Skala 1 & Tingkat mortalitas $30 \%$ \\
\hline Skala 2 & Tingkat mortalitas $40 \%$ \\
Skala 3 & Tingkat mortalitas $50 \%$ \\
Skala 4 & Tingkat mortalitas $80 \%$ \\
Skala 5 & Tingkat mortalitas $90 \%$ \\
\hline
\end{tabular}


KASUS

Kasus 1

Seorang pasien Ny A, berusia 45 tahun berat badan $60 \mathrm{~kg}$ dirujuk dengan diagnosa SAH dari salah satu rumah sakit daerah dengan keluhan kelemahan tubuh bagian kanan. Sebelumnya mengeluh nyeri kepala selama 3 hari, riwayat penyakit hipertensi dengan minum obat valsartan $80 \mathrm{mg}$ 1-0-0, terpasang nimodipin pump $50 \mathrm{cc} / 24 \mathrm{jam}$ sejak di rumah sakit daerah. Pasien datang tanpa keluhan sesak respirasi rate 18 x/menit, SpO2 98\% dengan oksigen masker $6 \mathrm{Lpm}$, perfusi hangat tekanan darah 109/62 mmHg. GCS E4V5M6, hemiparese kanan dan terpasang Folley kateter. Hasil pemeriksaan laboratorium: HB 12,4 leuco 19.840, HCT 36,1, PLT 219000, PTT/APTT 11/28, Na 141, K 3,6, GDS 127 HbA1C 5.

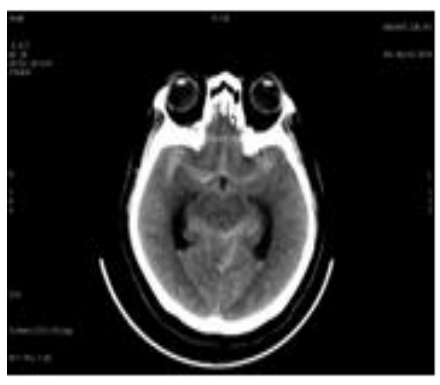

A

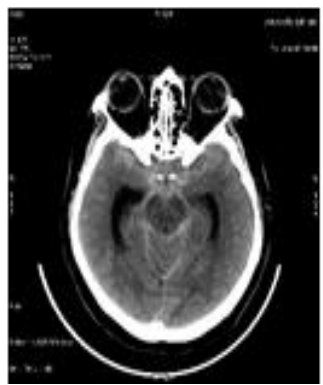

B

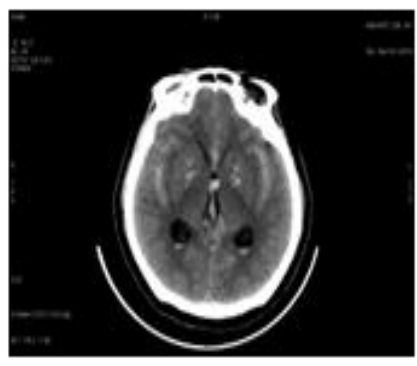

C

Gambar 1. CT scan kepala dan foto dada. A, B, C: SAH di cisterna pentagonal, cisterna crural, cisterna ambient, cisterna quadrigeminal. SAH minimal di fissure sylvii dan sulci fronto parietal kanan kiri. IVH di ventrike 11,11,111,1V disertai non communicating hydrocephalus.

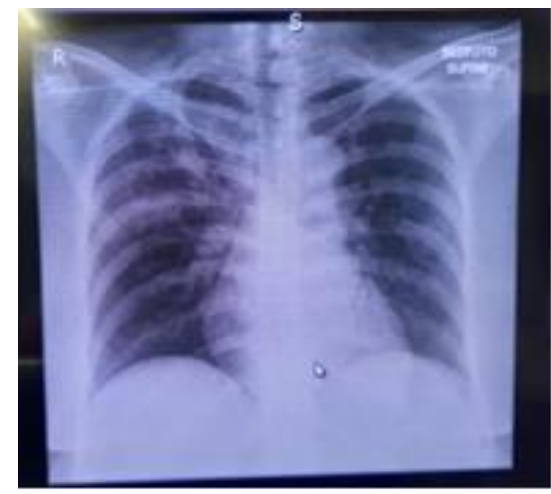

Gambar 2. Foto dada, kesan jantung paru dalam batas normal.

Menurut skala modifikasi fisher digolongkan grade 2 dengan risiko terjadi vasospasme sedang, tingkat mortalitas menurut skala Hunt dan Hess tergolong skala 2 dengan mortalitas 40\%. Pasien dipersiapkan dan dilakukan tindakan DSA + coiling. Pascatindakan pasien dirawat di intensive care unit (ICU). Pada hari ke 7 pasien pindah perawatan di ruangan dengan kondisi GCS tetap E4V5M6, selama di ICU maupun diruangan observasi balans cairan diusahakan seimbang, CVP 9-10 dan tekanan darah sistolik 120-140 $\mathrm{mmHg}$. 


\section{Kasus 2}

Pasien wanita 76 tahun, $60 \mathrm{~kg}$ dirujuk dari rumah sakit daerah dengan keluhan nyeri kepala setelah terpeleset 5 hari yang lalu, pingsan (-) muntah 1 kali CT ccan telah dilakukan 2 kali di rumah sakit daerah sebelumnya dengan SAH terkesan bertambah. Riwayat penyakit hipertensi (HT) dan diabetes mellitus
(DM) dengan mengkonsumsi irbesartan dan metformin. Pasien datang tidak ada keluhan sesak respirasi rate $20 \mathrm{x} / \mathrm{mnt}$ saturasi $99 \%$ dengan masker $\mathrm{O} 26 \mathrm{Lpm}$, perfusi hangat tekanan darah 160/70 mmHg N 74, GCS E3V5M6 PBI +3/+3, terpasang folley kateter terpasang nimodipin pump $10 \mathrm{mg} / 24$ jam dan nicardipin 0,5 mikro/kg bb/jam.

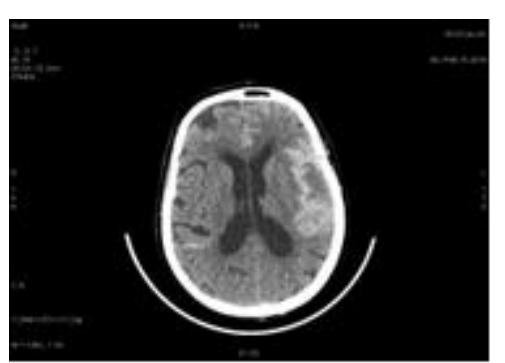

A

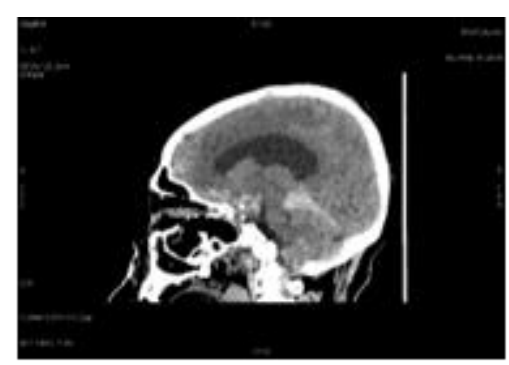

B

Gambar 3. CT scan kepala. A: hydrocephalus ringan. B: SAH dilobus parietal S dan basal cerebrum

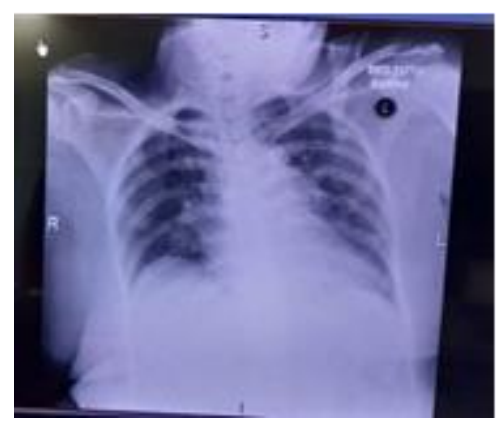

Gambar 4. Foto dada: kesan sklerotik arcus aorta, fibrosis di parakardial kiri, kesan bekas keradangan

Menurut skala modifikasi fisher digolongkan grade 2 dengan risiko terjadi vasospasme sedang, sedangkan tingkat mortalitas menurut skala Hunt dan Hess pada skala 3 dengan angka mortalitas sebesar 50\%. Hasil laboratorium: $\mathrm{Hb}$ 9,8 leukosit 21000 trombosit $98000 \mathrm{BT} / \mathrm{CT}$ 2/10 PT 9,4 APTT 29,3 SGOT/SGPT 25/17,BUN/Sc 34/0,58 GDS 198 SE:Na $135 \mathrm{~K} 2,35 \mathrm{Cl}$ 104 Alb 4,24, dilakukan transfusi pre 1 bag, TC 4 bag, $\mathrm{KCl} 50$ meq/24 jam, 2 hari setelah itu dilakukan DSA+coiling. Selama perawatan pasien di ICU tekanan darah sistolik berkisar $140 \mathrm{mmHg}$, balans cairan dijaga seimbang CVP 9-10 dan nimodipin tetap diberikan IV. Pada CT scan evaluasi pasca coiling hasil SAH luas berkurang dan tidak tampak area hipodense di brain parenchyme. Setelah 3 hari perawatan di ICU pasien alih rawat ke rumah sakit asal dengan alasan faktor biaya dengan GCS tetap E3V5M6.

\section{Kasus 3}

Pasien wanita 52 tahun, $65 \mathrm{~kg}$ ditemukan lemas, mual, sakit kepala dan keringat dingin di kamar mandi sebuah restoran, dibawa ambulan ke rumah sakit dalam 
kondisi tidak sesak, respirasi rate 18 $\mathrm{x} / \mathrm{mnt}$, saturasi $100 \%$ dengan nasal kanul $3 \mathrm{Lpm}$, perfusi hangat tekanan darah 122/67 mmHg nadi 74, dengan GCS E4V5M6, dipasang folley kateter. Hasil

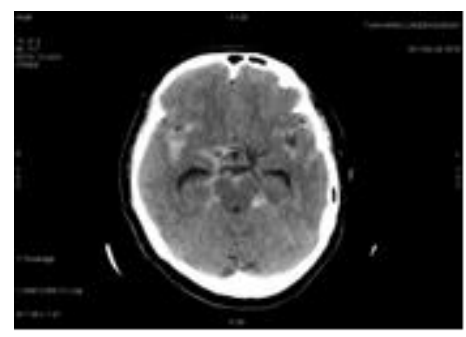

A laboratorium: $\mathrm{Hb} 11,2$, Ht 34,2, leukosit 10210, trombosit 218000, $\mathrm{NaK} / \mathrm{Cl}$ 137/3,07/105, BUN/Sc 20,8/0,56, SGOT/SGPT 17/11, GDS 164, Alb 4, BT/CT 2/10, PT 10,5, APTT 28,8.

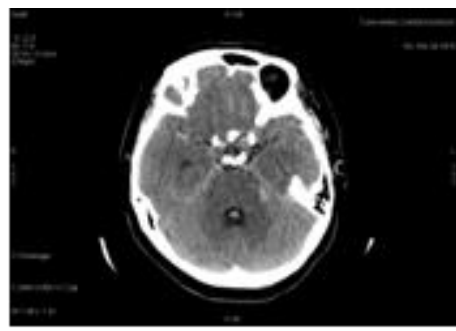

B

Gambar 5. CT scan kepala. A: SAH di cisterna pentagonal,cisterna ambient,cisterna quadrigeminal, fissure sylvii kanan. B: IVH di ventrikel Lv, tidak ada shift dari midline struktur.

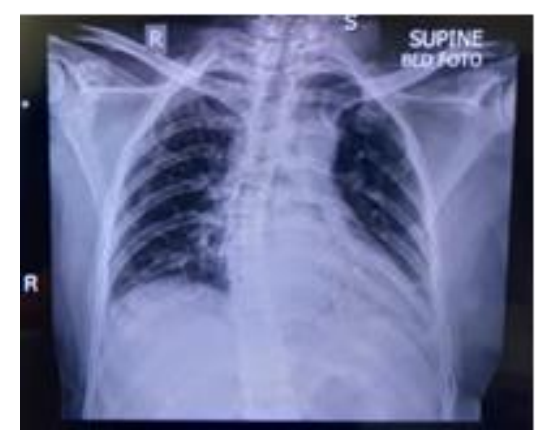

Gambar 6. Foto dada. Kesan sklerotik arcus aorta, paru dalam batas normal.

Setelah diagnose SAH ditegakkan, nimodipin diberikan dengan dosis 10 $\mathrm{mg} / 24$ jam. Menurut skala modifikasi fisher digolongkan grade 2 dengan risiko terjadi vasospasme sedang, sedangkan tingkat mortalitasnya pada skala 2 dengan angka mortalitasnya $40 \%$. Setelah 8 hari perawatan dan mendapat penjelasan risiko terjadinya perdarahan ulang dan meningkatnya angka mortalitas, maka keluarga menyetujui dilakukan tindakan DSA + clipping. Selama perawatan di ICU tekanan darah dipertahankan normal atau sligh hipertensi, pemberian cairan dipertahankan seimbang. GCS tetap E4V5M6 dan pasien dalam keadaan stabil.

\section{PEMBAHASAN}

Aneurisma serebri sering tidak terdeteksi pada banyak kejadian dan sering ditemukan sudah dalam keadaan pecah atau tidak sengaja ditemukan saat melakukan pemeriksaan patologi intrakranial. ${ }^{1}$ Penilaian tingkat risiko terjadi vasospasme menggunakan skala modifikasi fisher digambarkan dengan 4 tingkat. Tingkat 1 risikonya rendah, tingkat 2 risikonya sedang, tingkat 3 risikonya tinggi dan tingkat 4 risikonya sangat tinggi. Dari ketiga kasus diatas, semua kasus dalam tingkat 2. Sedangkan penilaian yang memprediksi mortalitas bila terjadi SAH dengan "Hunt and Hess Scale" mempunyai 5 tingkatan. Dari ketiga pasien diatas, 1 dan 3 
dikategorikan pada skala 2, sedangkan pasien 2 pada skala 3. Kematian biasanya disebabkan oleh: cedera neurologis akibat perdarahan awal, perdarahan ulang (rebleeding) dan DCI. ${ }^{1}$

Terjadinya aSAH akan dapat mempengaruhi fungsi tubuh lainnya, pada jantung bisa terjadi kelainan elektrokardiografi, ${ }^{4}$ termasuk perubahan gelombang ST dan T yang menunjukkan iskemia miokard dan perpanjangan QT dan gelombang U selain itu dapat juga terjadi aritmia supraventrikular dan ventrikel, peningkatan kadar troponin dan disfungsi miokard tanpa vasospasme koroner. ${ }^{1}$ Mekanisme terjadinya gangguan belum diketahui pasti, kemungkinan penyebabnya adalah aktivitas simpatis bersamaan dengan disfungssi parasimpatis yang mengakibatkan inflamasi miosit jantung. Peningkatan troponin dikaitkan dengan risiko komplikasi kardiovaskular dan DCI. ${ }^{1}$

Pada paru dapat terjadi edema paru neurogenic (NPE) diduga disebabkan oleh pelepasan asimpatis masiv akibat cedera neurologis dan berhubungan dengan berkurangnya fungsi sistolik ventrikel kiri global. ${ }^{1}$ NPE mencerminkan keparahan SAH dan terkait dengan hasil yang buruk. Dari ketiga kasus diatas tidak ditemukan gambaran udema paru.

Peningkatan tekanan darah setelah SAH dikaitkan dengan mortalitas yang tinggi, namun pengelolaan hipertensi secara agresif selalu menjadi masalah, mengingat bahwa tekanan darah yang tinggi diperlukan untuk mempertahankan tekanan perfusi otak (CPP). ${ }^{1}$ Aktivitas simpatatik setelah SAH merupakan penyebab terjadinya hipertensi. Peningkatan tekanan darah yang berkelanjutan meningkatkan risiko terjadinya rupture dan perdarahan ulang aneurisma. Oleh karena itu tekanan darah dipertahankan disekitar 140 mmHg agar aman untuk mengurangi risiko perdarahan ulang tanpa meningkatkan risiko komplikasi iskemia. ${ }^{1}$ Pada ketiga kasus diatas tekanan darah sistolik berkisar 140 mmHg. ${ }^{1}$ Labetalol, esmolol dan nicardipin adalah obat yang digunakan untuk mengurangi hipertensi pada pasien SAH, namun nicardipin memberikan kontrol tekanan darah yang lebih baik dibandingkan dengan labetalol pada pasien SAH dengan hipertensi, ${ }^{1}$ vasodilator seperti NTG, hydralazine, sodium nitroprusside harus dihindari karena vasodilatasi dapat meningkatkan aliran darah dan kemungkinan memperburuk ICP. ${ }^{1}$

Pasien SAH dengan hiperglikemia mempunyai risiko meningkat untuk terjadinya perburukan klinis., ${ }^{1,2,13,14}$ Hiperglikemi yang terjadi berkaitan dengan lamanya perawatan di ICU. Kontrol gula darah sangat diperlukan, The European Stroke Organization merekomendasikan gula darah diatas $180 \mathrm{mg} / \mathrm{dL}$ diperlukan pengobatan. ${ }^{2}$

Penanganan dini baik clipping bedah maupun coiling endovascular akan mencegah adanya perdarahan ulang ${ }^{1}$ dan akan memungkinkan pencegahan vasospasme yang efektif. Pada kasus ke 3 intervensi (DSA+clipping) dilakukan hari ke 8 dan pasien tidak mengalami penurunan kesadaran.

Mekanisme DCI belum diketahui dengan pasti, tetapi kemungkinan multifaktorial. Biomarker untuk memperkirakan perkembangan DCI belum ada, namun pada SAH selalu disertai sindrom respons peradangan sistemik sebagai penanda inflamasi seperti c-reaktive protein (CRP) dan 
interleukin (IL-6) yang meningkat secara dini, dan peningkatan yang lebih tinggi dikaitkan dengan hasil neurologis yang buruk. ${ }^{1}$

Pencegahan DCI biasanya diterapi dengan nimodipin, sirkulasi darah dijaga normal (euvolume) dan tekanan darah dipertahankan stabil sekitar 120-140 $\mathrm{mmHg}$. Nimodipin adalah antagonis kalsium dan pemberian oralnya bermanfaat dalam pengelolaan pencegahan vasospasme dan DCI. Berdasarkan bukti saat ini penggunaan IV tidak dianjurkan. ${ }^{1,4,5,9,11}$ Pada ketiga kasus diatas setelah diagnose SAH ditegakkan langsung diberikan nimodipin. Sampai saat ini nimodipin adalah satu-satunya obat untuk pencegahan vasospasme otak dan DCI. ${ }^{5}$ Pengobatann lainnya yang diusahakan digunakan adalah pemberian magnesium untuk pencegahan vasospasme namun tidak direkomendasi pemakaaiannya karena tidak ada bukti yang mendukung penggunaan magnesium iv setelah $\mathrm{aSAH}^{10}$ demikian juga pemberian aminosteroid non glucocorticoid, clazosetan yang merupakan antagonis endotelin-1 dihentikan percobaannya sebelum waktunya. ${ }^{1}$ Demikian juga pada pemakaian statin maupun penggunaan agen anti platelet dengan memakai heparin berat molekul rendah belum direkomendasikan. ${ }^{1}$ Pemberian terapi Triple (hipertensi, hypervolemia, hemodilusi) belum divalidasi. Hipertensi adalah komponen yang lebih penting dari terapi $3 \mathrm{H}$, hipervolume menyebabkan penurunan oksigenasi jaringan otak, pemberian berlebihan cairan berhubungan dengan menjeleknya fungsi jantung dan paru, hemodilusi berhubungan dengan penurunan oksigen delivery. ${ }^{1,4}$

Teknik untuk mengetahui adanya vasospasme dapat dilakukan dengan berbagai cara yaitu dapat dengan cara serebral angiografi, teknik ini digunakan untuk mendiagnose vasospasme arteri intrakranial, namun invasif sehingga dapat menyebabkan stroke karena deseksi arteri, emboli dan rupture arteri. Computed tomography angiogram (CTA) juga dapat digunakan untuk mendiagnosa vasospasme, Namun praktis tidak untuk pemantauan harian pada pasien di ICU. Transcranial doppler (TCD) memiliki keuntungan sebagai teknik non invasif dan mudah dibawa kemana mana. ${ }^{1,4,7}$

Pasien dengan SAH biasanya mengalami abnormalitas cairan dan elektrolit. hiponatremia lebih sering terjadi daripada hypernatremia ${ }^{1,2}$ yang disebabkan terjadinya SIADH. ${ }^{1}$ Sindrom ini biasanya menunjukan trias: hiponatremia, hypovolemia dan konsentrasi $\mathrm{Na}$ dalam urin yang tinggi. Pasien dengan SIADH cenderung menunjukan normovolemia atau hypervolemia ringan. Hipernatremia juga dapat ditemukan pada pasien $\mathrm{SAH}$ dikarenakan kemungkinan iatrogenik akibat pemberian manitol atau HTS. ${ }^{1}$ Hypernatremia setelah SAH berkaitan dengan outcome yang jelek dan kematian. ${ }^{1,2}$

\section{KESIMPULAN}

Terapi pencegahan terjadinya DCI dilakukan dengan pemberian: nimodipin, mempertahankan sirkulasi darah normal (euvolume) dan tekanan darah dipertahankan sligh hipertensi, oleh karena itu penelitian diperlukan untuk menemukan obat yang lebih baik.

Skrining akan lebih baik juga hemat biaya untuk pencegahan aSAH, juga disarankan terhadap mereka yang memiliki kerabat dekat dengan SAH. 
DAFTAR PUSTAKA

1. D'Souza S. Aneurysmal Subarachnoid Hemorrhage. $J$ Neurosurg Anesthesiol Volume 27 No.3. July 2015

2. Okazaki T, Kuroda Y. Aneurysmal subarachnoid hemorrhage: intensive care for improving neurological outcome. Journal of intensive care 2018

3. Marder CP, Narla Vinod, et al. Subarachnoid Hemorrhage: Beyond Aneurysms. AJR 2014:202:25-37

4. Connolly E. Sander, et al.Guidelines for management of aneurysmal subarachnoid hemorrhage. Stroke. 2012;43:1711-1737

5. Findlay JM. Cerebral vasospasm: A Review. Can J Ne urol Sci. 2016 jan;43(1):15-32

6. Macdonald R L, Schweizer T A. Spontaneous subarachnoid haemorrhage. The lancet vol 389 february 11, 2017

7. Frontera Jennifer A, et al. Defining Vasospasm After Subarachnoid Hemorrhage. Stroke 2009 jun; 40(6): 1963-8

8. Pluta Ryszard M,et al. Cerebral Vasospasm following subarachnoid hemorrhage: time for a new world of thought. Neurol Res 2009 Mar:31(2):151-158

9. Allen George S,et al. Cerebral Arterial Spasm: A controlled trial of nimodipin in patients with subarachnoid hemorrhage. $N$ Engl J Med 1983;308:619-24
10. Siasios Ioannis, et al. Cerebral Vasospasm Pharmacological Treatment: An update. Neurology Research International 2013(11):571328

11. Feigin V L,et al. Calcium antagonists in patients with aneurysmal subarachnoid hemorrhage: Asystematic review. Neurology 1998;50(4)

12. Kruyt Nyika D,et al. Hyperglycemia in aneurysmal subarachnoid hemorrhage: a potentially modifiable risk factor for poor outcome. Journal of cerebral blood flow \& metabolism (2010) 30, 1577 $-1587$

13. Kruyt Nyika D,et al. Hyperglycemia and clinical outcome in aneurysmal subarachnoid hemorrhage. Stroke 2009; 40:e424

14. Grasso Giovanni,et al. Management of aneurysmal subarachnoid hemorrhage: state of the art and future perspectives. Surgery neurology international 2017: 8:71.

15. Lawton $M \mathrm{~T}$, Vates $\mathrm{G}$ E. Subarachnoid haemorrhage. $N$ Engl J Med 2017 juli 20;377 (3):257 266 